\title{
A Wireless Camera Node with Passive Self-righting Mechanism for Capturing Surrounding View
}

\author{
Kuniaki Kaw abata ${ }^{1}$, Hideo Sato 2 , Tsuyoshi Suzuki ${ }^{2}$ and Yoshito Tobe ${ }^{2}$ \\ ${ }^{1}$ RIKEN(The Institute of Physical and Chemical Research) \\ ${ }^{2}$ Tokyo Denki University \\ elpan
}

\section{Introduction}

Japan is a land of frequent earthquakes, and developing effective means for preventing and mitigating disasters in their aftermath is a matter of deep and widespread concern. The time and location of their occurrence is essentially unpredictable, and interest therefore centers on preventing and mitigating damage. A key prerequisite for effective mitigation is rapid, accurate appraisal of conditions in the stricken region. For this purpose, the development of systems for concurrent, parallel information gathering, capable of covering a broad range of affected areas and conditions, is critical. In the DDT Project, 'Development of Advanced Robots and Information Systems for Disaster Response.' of the Japanese Ministry of Education, Culture, Sports, Science and Technology (MEXT), the development effort for rescue robots and other next-generation basic technologies for disaster prevention and mitigation has included the development of interlinked rescue robots, airborne vehicles, sensors, and other elements of disaster area information gathering technologies (Tadokoro, 2009).

A related recent development has been the trend toward ubiquitous computing (Weiser, 1991), data carriers (Takeda, 1991), and related technologies, with research and development in progress for the creation of intelligent information environments to support and aid in daily life and living. In parallel with these advances, the authors have developed an intelligent data carrier (IDC) for rescue, designed to support the search for victims immediately after an earthquake (Kurabayashi et al., 2003); (Asama et al., 2005); (Kawabata et al. 2006); (Hada et al., 2006). The rescue $\mathrm{DC}$ is a small device with wireless radio communication capability, for installation in living environments. In the wake of an earthquake, this device can send out voice calls to any who might be trapped in the rubble and record their responses. With multiple deployments, the IDCs enable parallel searches for victims throughout the stricken area. In a separate study, Takizawa et al. (2007) has applied RFID (Radio Frequency Identification) technology to the development of an information transmission system in which wireless tags are permanently installed along streets and other routes to collect information on the stricken area, so that victims trying to leave the area and rescue personnel can perform non-contact automated gathering of the information. In the wake of a disaster, however, the rescue DCs may not be available where 
they are needed. In the information transmission system of Takizawa as well, it is necessary to install the electronic tags in the environment in advance. In many cases, the sites in need of information gathering cannot be determined until after the disaster. It is therefore desirable to develop information terminals which can be readily deployed after a disaster, for efficient information gathering at appropriate locations.

Some sensor systems and devices have already been developed for deployment following hazards. Inoue et al.(2005) have developed a ball-shaped probe that can be thrown into rubble following a disaster, and evaluated the configuration for mobility in rubble. The search ball contains a camera with motor-controlled sensing direction, for information acquisition, but it is not effective for use in disaster areas requiring information acquisition and collection in parallel with multiple sites. Remington Arms Co. of the United States provides a product named the Eye Ball for on-site information gathering at crime scenes such as hostage standoffs and for on-site security. It is a ball-shaped camera that can be thrown into a target area and then autonomously adjust its attitude, like a self-righting Japanese Dharma doll, on a floor or other level surface. Under control signals from the outside, the Eye Ball rotates its internal camera to scan the area, thus enabling acquisition of information on the surrounding interior. The information is relayed using a video transmitter, however, this would make simultaneous operation of multiple sensors difficult because of the number of channels required for such a purpose.

Interest has grown rapidly in sensor network technology (Ando et al., 2005) for environmental information gathering and sharing by organically linked sensor nodes in a wireless network within a given area, and various efforts are in progress for developing related technologies. Fukatsu and Hirafuji (2005) have developed an environment monitoring system which incorporates fixed wireless nodes in a broad agricultural area, linked to a web browser. Fixed network systems such as these are effective in cases where the measurement sites are determined in advance, but in the case of disasters or other events, in which the appropriate sites and circumstances are largely unpredictable, a capability for ad hoc network construction is essential.

Wireless sensor network technology holds great promise for rapid information gathering and sharing over a broad disaster area, which requires rapid construction of an information infrastructure appropriate to the conditions in the area together with simultaneous parallel collection of information acquired at additional sites. In such circumstances, it is essential to include identification of the time and place of acquisition together with the information acquired by the sensors, to enable presentation of the information in a coherent, organized form for browsing and observation.

In this report, we propose the basic concept of a camera-based sensor node that can be readily deployed amidst rubble and irregular land surfaces, with the capability for wireless network construction to enable information gathering from a disaster area, and report on experimental trials held to verify the function and performance of prototype camera nodes based on this concept.

\section{Design concept}

Many studies have focused on sensor nodes for advance mounting on ceilings, streetlights, and other structures (Nakata \& Kushiro, 2007). In a disaster, however, the position and 
orientation of pre-installed nodes may change, the nodes themselves may even be damaged or inoperable, and, in any event, the sites requiring information gathering and monitoring will be largely unknown until after the disaster strikes. A sensor node is therefore needed which can be readily deployed in an area following a disaster, in highly irregular topography. In such circumstances, moreover, the existing information infrastructure may be severely damaged and disrupted. An effective system should therefore be able to operate independently of ordinary infrastructure, with a capability for construction of a selforganizing information network following deployment, to enable reliable transmission of information from the sensors on their surroundings and the time and location of the acquired information.

In performing the specification design for a sensor node to meet these needs, we have identified the following as essential functions.

- Power supply self-contained for autonomous drive.

- Bilateral wireless communication and self-organizing network construction.

- Acquisition of information on surroundings, position, and time.

- Maintenance of specified sensor attitude, regardless of topography at placement site.

The sensor node must also contain its own power source, such as a battery, to enable continuous operation of its autonomous drive and other functions for a sufficient period in the absence of lifeline utilities and infrastructure, which may be the case in disaster areas.

For gathering and consolidation of information on the disaster area, an information infrastructure must be constructed in the actual area, with connection among the information terminals. The sensor must be capable of wireless two-way communication and participation in self-organized, on-site construction of the communication network. It must therefore also enable temporal and spatial coordination, as the information it acquires will otherwise be meaningless when consolidated with information acquired at other sites. For this reason, it must be capable of determining "when and where" it acquires the information, and attach it to the acquired data. For coherent information gathering in the disaster area, in short, the sensor nodes must be able to form a network and provide a means for reliable consolidation of the acquired information without information loss.

Sensor attitude and sensing direction are also essential considerations. Whether the information acquisition is directional or omnidirectional, the orientation of the sensor node at each site during data acquisition is important. If the sensor is directional and points toward the surface on which it has been placed, it may entirely preclude acquisition of meaningful information. One solution would be to deploy multiple sensors at a single site in accordance with the data acquisition characteristics of the sensor and thereby eliminate blind spots, but this tends to increase the difficulty of achieving compact hardware design and obtaining low energy consumption. Sensor attitude is, in any case, a key consideration, as the site surfaces may be uneven, and it is necessary to ensure attainment of appropriate sensor attitude regardless of the surface angle. In summary, for any extended period of use, it is desirable to minimize the size, weight, and complexity of the sensor node, its drive and control units, and thus its energy consumption, and to provide a means of effective sensor attitude control with the smallest possible number of sensor components while providing a broad field of information acquisition and sufficient level of information acquisition.

For effective information acquisition in a disaster area, a sensor node that satisfies all of these requirements is necessary. 


\section{Design and fabrication of camera node}

We designed and fabricated of a sensor node prototype to meet the above requirements. A camera is used as the sensor, to enable intuitive visual observation and ascertainment of the acquired information by rescue personnel and others, and a fisheye lens was selected to provide surroundings information acquisition. To distinguish this sensor node from other types and versions, we refer to it below as the "camera node" or simply the "node". Its key design parameters included the ability to visually recognize objects and structures (assumed to be approximately $1.7 \mathrm{~m}$ in size) located $5 \mathrm{~m}$ from the camera node as well as movement at close-range distances of $1-2 \mathrm{~m}$.

\subsection{Passive self-righting mechanism}

The external appearance and the internal structure of the fabricated prototype is shown in Fig. 1. The acrylic shell is $2.8 \mathrm{~mm}$ thick and $250 \mathrm{~mm}$ in diameter. The gross weight is $3.5 \mathrm{~kg}$. The camera node consists of a core module composed of mounted computer and peripheral devices, sensors, battery, and other components, enclosed in the acrylic shell. Six ball rollers are mounted on the core module and maintain contact with the shell body. The core module is thus supported inside the shell by the ball rollers, yet free to rotate inside the shell under the force of gravity. This passive self-righting structure keeps the camera vertical and facing upward without the use of actuators or other devices, enabling acquisition of omnidirectional images with the same geometrical attitude regardless of the node orientation and the environment.
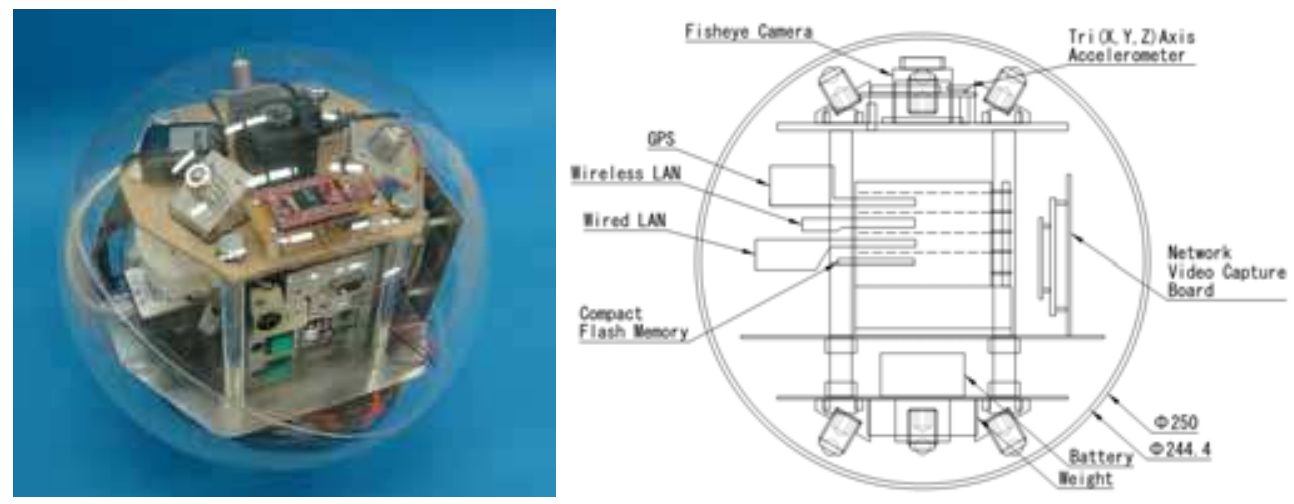

Fig. 1. A Prototype of Wireless Camera Node with Passive Self-righting Mechanism

The Cyclops (Chemel et al., 1999) and Omniclops (Schempf et al., 1999) are also spherical devices containing a camera and designed for uses similar to those envisioned in the present study, but the geometrical attitude of the camera is controlled by an electric motor and is thus essentially different from the passive control employed in our camera node, which enables higher energy efficiency. 


\subsection{Internal system components}

The internal system components of the camera node are shown in Fig. 2 and Table 1. The computer module at the heart of the camera node, which performs the data processing and also serves as the mount for the sensor, contains an embedded Linux OS-based core from the Rescue Communicator (R-Comm, Mitsubishi Electric Information Technology) (Hada et al., 2006). Other functional components include a CF memory card, a wireless LAN adaptor, a wired LAN adaptor utilized for connecting image capture card, a CMOS camera with fisheye lens (OPT, NM-30) as the sensing device, and a GPS locator, mounted in four compact flash memory card slots (CF slots).

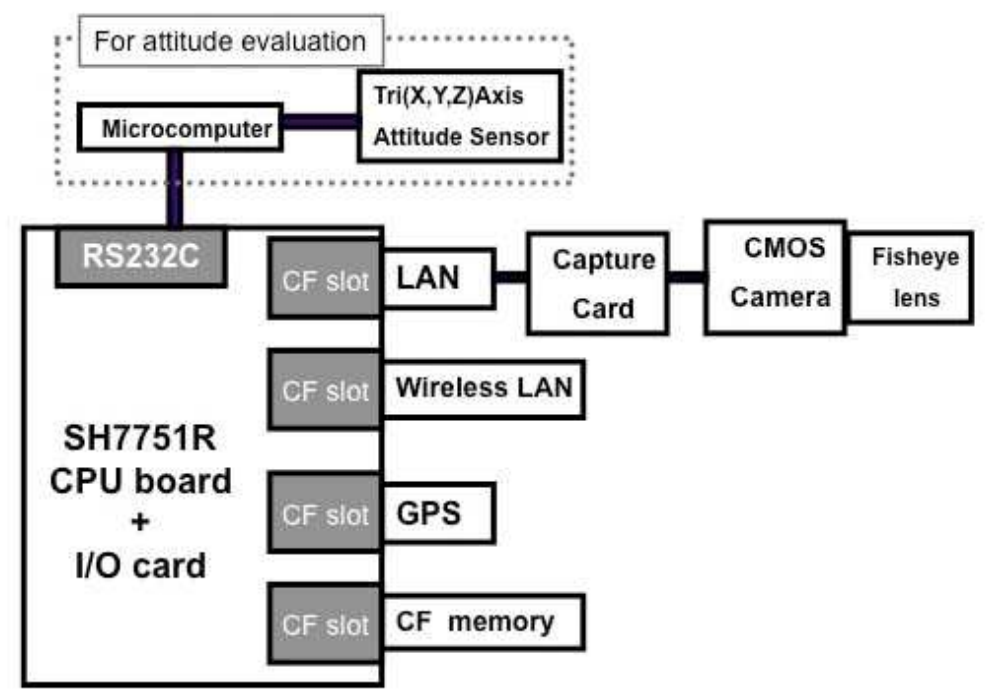

Fig. 2. System Configuration of Wireless Camera Node

\begin{tabular}{|l|l|}
\hline CPU & $\begin{array}{l}\text { SH7751R } \\
\text { (internal bus 100 MHz, } \\
\text { system bus 25 MHz) }\end{array}$ \\
\hline OS & $\begin{array}{l}\text { CELinux1.0 } \\
\text { (Kernel2.4.20 base) }\end{array}$ \\
\hline SDRAM & $32[\mathrm{MB}]$ \\
\hline Flash ROM & $8[\mathrm{MB}]$ \\
\hline Peripherals & $\begin{array}{l}\text { Wireless LAN (IEEE802.11b), } \\
\text { CMOS camera with fish-eye lens, } \\
\text { GPS adaptor }\end{array}$ \\
\hline Battery & $\begin{array}{l}+7.2[\mathrm{~V}], 3700[\mathrm{~mA}] \text { (for sensors) } \\
+6[\mathrm{~V}], 2500[\mathrm{~mA}] \text { (for computer) }\end{array}$ \\
\hline
\end{tabular}

Table 1. Specification of Wireless Camera Node 
An internally mounted battery supplies the electric power necessary for the autonomous drive. Time management on the Linux OS and locating by GPS enables attachment of temporal and spatial identifiers to the acquired information (i.e., the video information). Files are saved with time, position, and other information embedded, for easy, intuitive understanding in subsequent browsing.

For network formation, the AODV-uu ad hoc on-demand distance vector (AODV) protocol is also incorporated to enable self-organizing network construction. It was confirmed that camera node operation was possible for about $5 \mathrm{~h}$ with the AODV in continuous operation. The attitude sensor shown in Fig. 2 was installed to measure the attitude of the core module of the camera node in the following experiments.

(a) The manuscript must be written in English, (b) use common technical terms, (c) avoid abbreviations, don't try to create new English words, (d) spelling: Follow Merriam Webster's Collegiate Dictionary, Longman or Oxford Dictionaries.

\section{Experiments}

The camera node was subjected to the following experiments, to verify its capability for achieving the basic functions described above.

\subsection{Camera node placement experiment}

We investigated the capability of the passive self-righting mechanism in the camera node to self-right of the camera, as illustrated in Fig. 3.

The camera node was released on a 15 degree incline in the environment shown in Fig. 3 and allowed to roll down the incline and across the floor until it stopped, as shown in Fig. 4. In this experiment, an attitude sensor was installed as illustrated in Fig. 2, to measure the roll (rotation about the X-axis), pitch (rotation about the Y-axis), and an absolute value of yaw (rotation about the vertical Z-axis) of the core module as shown in Figs. 5.

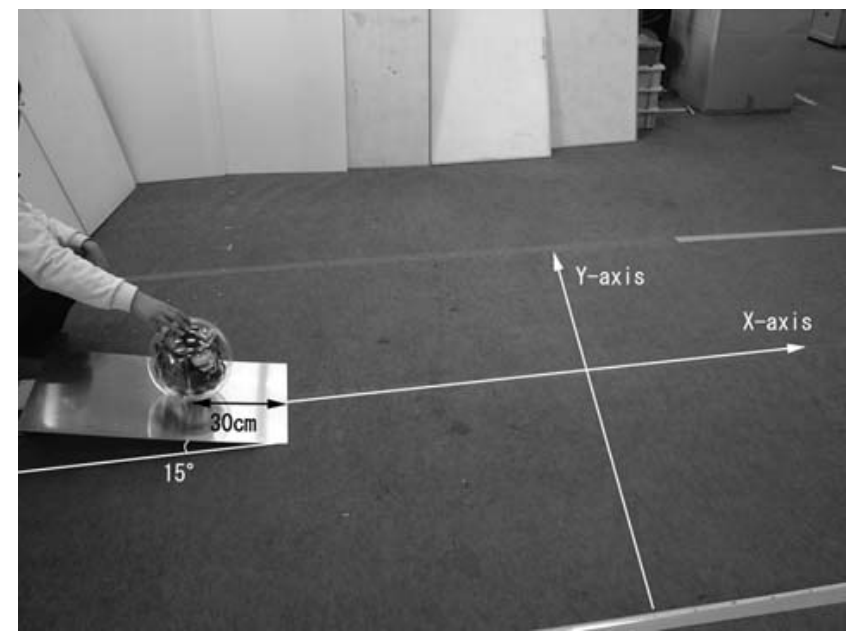

Fig. 3. Setup for Camera Node Setting-up Experiment 

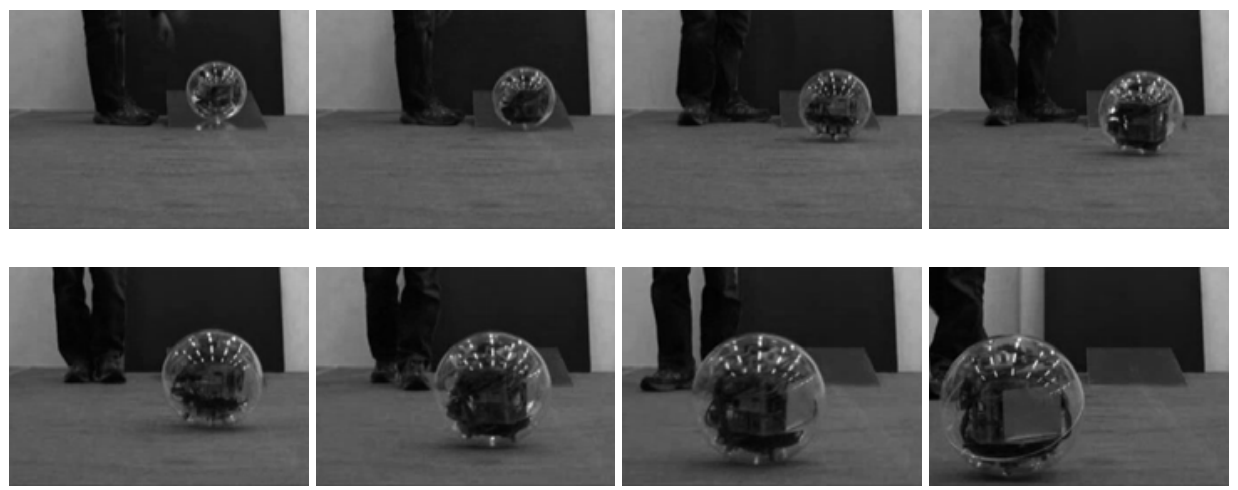

Fig. 4. Outlook of Setting-Up Experiment

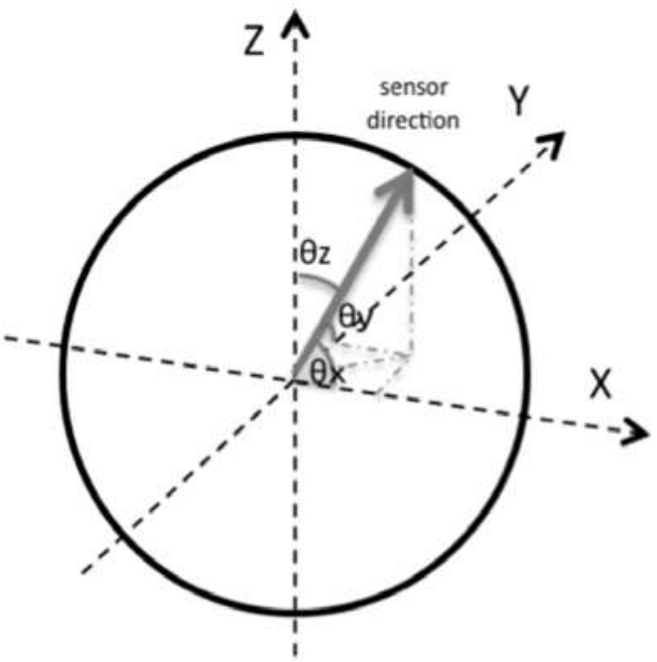

Fig. 5. Coordination for Camera Direction

The final attitude of the core, found from multiple trials, is shown in Fig. 6. The final attitude was generally within five degrees of the three axes. Although this depends on imaging conditions, given that the divergence is within five degrees, theoretical calculation shows that about one-half ( $2-3$ pixels) of a $1.7-\mathrm{m}$ object located $5 \mathrm{~m}$ from the lens (thus about 5 pixels for the whole-object length) will be captured with the orthogonal fisheye lens in the camera node, even if the divergence is in a direction involving partial loss of the target image. In the experiments, it was found that for an object extending over approximately 910 pixels in the full image, with an attitude divergence of five degrees in the direction of image loss, the object image still extended over approximately 6-7 pixels, thus confirming a sufficient capability for visual on-screen detection of object movement. These results show that the range of attitude error found in the experiment permits attainment of the initial performance objective of visual object recognition, and thus verify the effectiveness of the passive self-righting mechanism. 


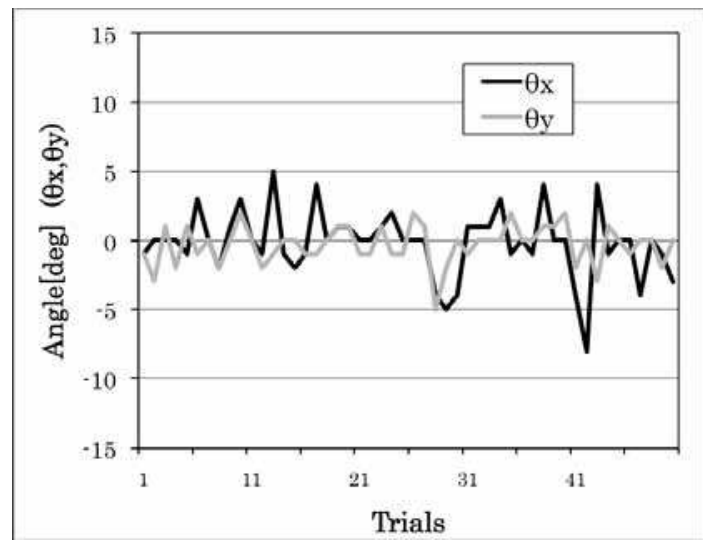

(a) Measured Sensor Attitude in X-axis and Y-axis

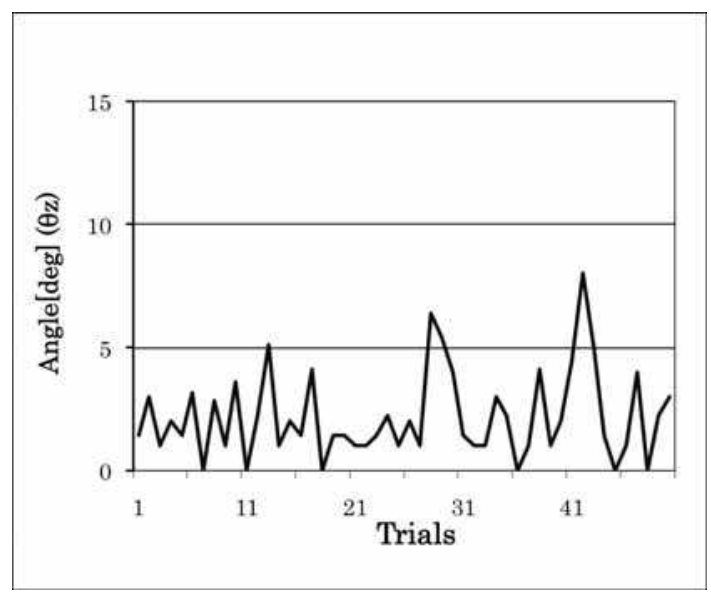

(b) Calculated Sensor attitude in Z-axis

Fig. 6. Experimental Result of Setting-Up a Camera Node

Similar results were obtained in an outdoor experiment as well when the camera node was rolled by hand, again confirming the vertical orientation of the camera by the passive selfrighting mechanism.

The basic design concept assumes visual inspection of the acquired images to investigate the area around the camera node. As the vertical orientation of the camera with the fisheye lens enables information acquisition, the results of this experiment confirm the basic validity of this concept.

A further task remains concerning the shell body, made of acrylic plastic in the prototype. In the final version of the sensor node, the use of polycarbonate or some other material of high impact resistance is envisioned, to withstand possible impacts by falling objects due to aftershocks and falls by the node itself. A related task is the development of a systematic program for redundant deployment of the sensor nodes and reserve units for replacement of disabled units (Suzuki et al., 2008), to ensure preservation of the network connection and information gathering functions. 


\subsection{Basic experiment on video transmission and communication}

We next performed a basic experiment on transmission of the video images via the ad hoc connections of the camera node. Two views of the outdoor experimental site are shown in Fig. 7. To facilitate investigation of the basic performance, we chose a location providing good visibility. In each trial, the camera node was placed at an arbitrary position, established an ad hoc network with the host PC, and, on a "shoot" signal from the host PC, performed video information acquisition for $5 \mathrm{~s}$.

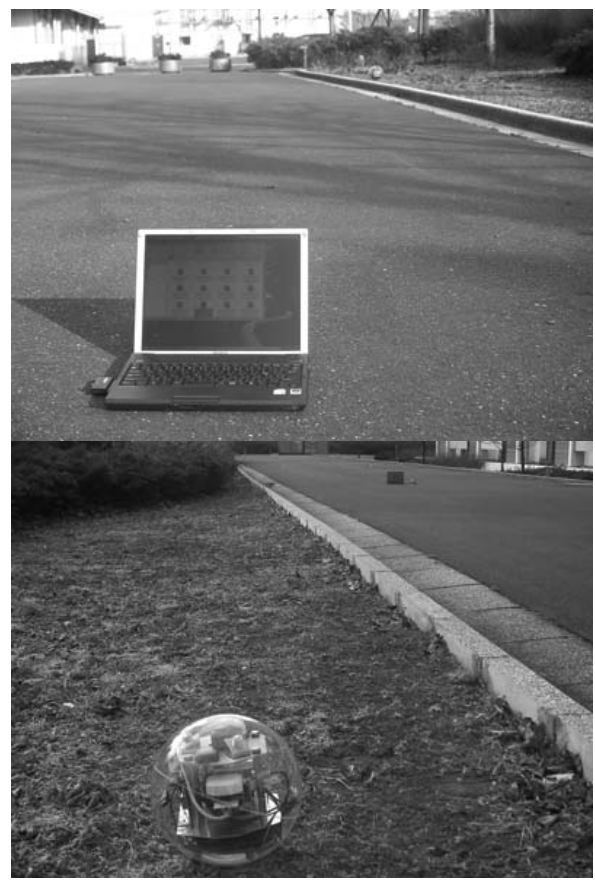

Fig. 7. Setup for Video Capturing and File Transferring Experiment (In case of distance $=15[\mathrm{~m}]$ )

Video captures of images sampled at 1-s intervals from a 5-s video file display on the PC, after shooting video and data transmission (transmission distance, $15 \mathrm{~m}$ ) by the camera node, are shown in Fig. 8.

For each image, as indicated in the figure, information related to the acquired video is included in the video filename, in the form "date+time+GPS position information+imaging/ image capture length (sec)+name of acquiring device.ASF (file format-specifying extension)". As shown in Fig. 9, the filename consolidates the data on the time that the video recording began the position, and the file format.

The images shown in Fig. 8(a) are video captures of the image obtained by the camera node using video streaming. They demonstrate the capability to visualize trees (about $2 \mathrm{~m}$ tall) and building windows at about a $10-\mathrm{m}$ distance from the device. The images shown in Fig. 8(b) are from the same position, but include the image of a person walking past the camera node. The person passed the camera node at a distance of about $1 \mathrm{~m}$, and this image clearly provides sufficient detail for confirming movement. 


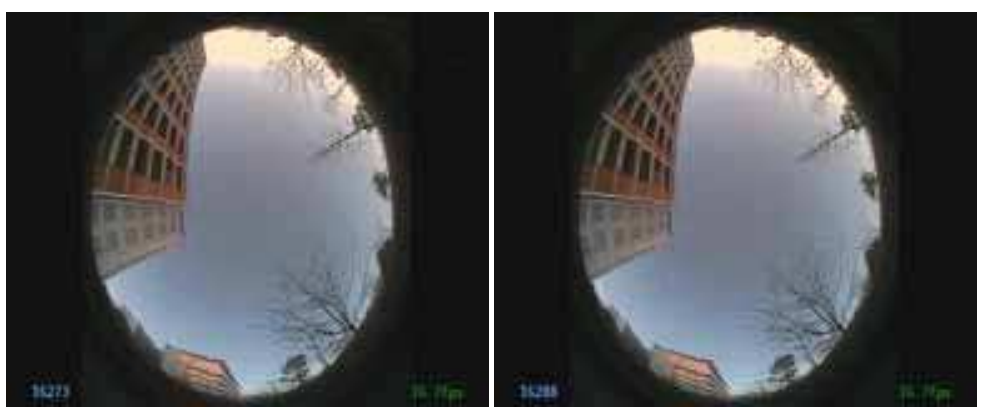

(a) Captured video filename: 2008.02.28.17.20.17.3546.5874,N,13936.6583,E.5.rcomm1.ASF

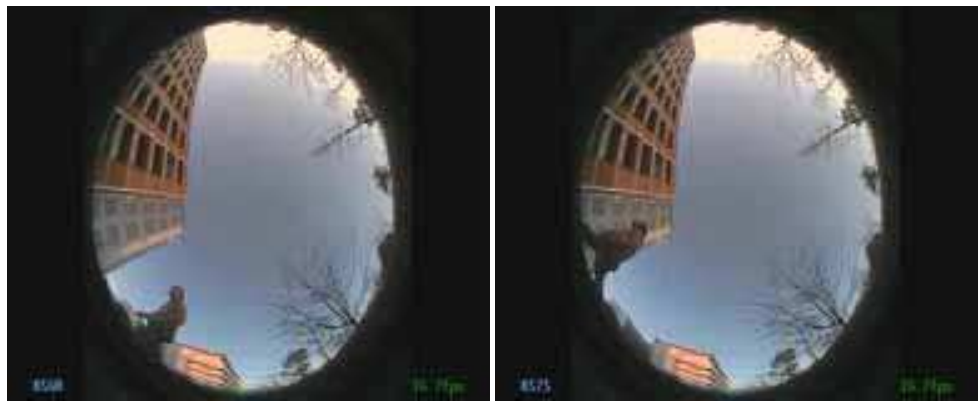

(b) Captured video filename: 2008.02.28.17.12.22.3546.6918,N,13936.5564,E.5.rcomm1.ASF

Fig. 8. Examples of Captured View by Developed Wireless Camera Node

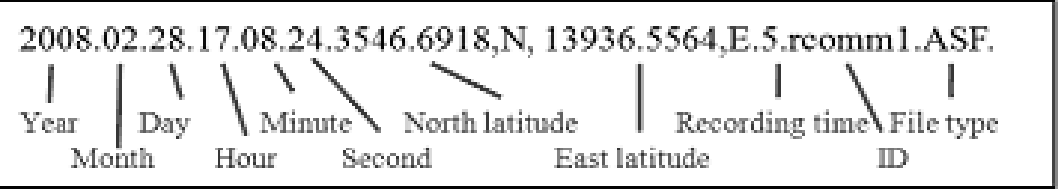

Fig. 9. A Format of filename for including the conditions

The experimental results verify that it is possible to transmit on-site information acquired by the embedded CMOS camera, together with the acquisition time and position and other related information, to a separate terminal via a network formed by ad hoc connection. The acquired image is distorted by the fisheye lens, but can be converted to a panorama view by lens reverse-modeling computation after acquisition.

We next investigated the video transmission capability of this system, in the aforementioned outdoor environment. The imaging data was acquired as 360-kB-sized video (resolution CIF standard $352 \times 288$ pixels) file in advanced streaming format (ASF), at distances of 15 and 30 $\mathrm{m}$ from the camera node to the PC, outdoors, using file transfer protocol (FTP).

At the transmission distance of $15 \mathrm{~m}$, the duration of the experiment was $10 \mathrm{~min}$ and $35 \mathrm{sec}$, in which 49 video files were transmitted. The mean time per file was thus $12.96 \mathrm{~s}$ (transmission rate: $0.23 \mathrm{Mbit} / \mathrm{s}$ ). Similarly, at the transmission distance of $30 \mathrm{~m}$, the experiment duration was $10 \mathrm{~min}$ and $52 \mathrm{~s}$ with transmission of 43 files, and thus an mean time per file of $15.16 \mathrm{~s}(0.19$ 
Mbit/ s). These mean times include the entire transmission process based on AODV and FTP, as indicated in Fig. 10. As shown, some variation occurred in file transmission time, but the results clearly confirm the capability for stable transmission.

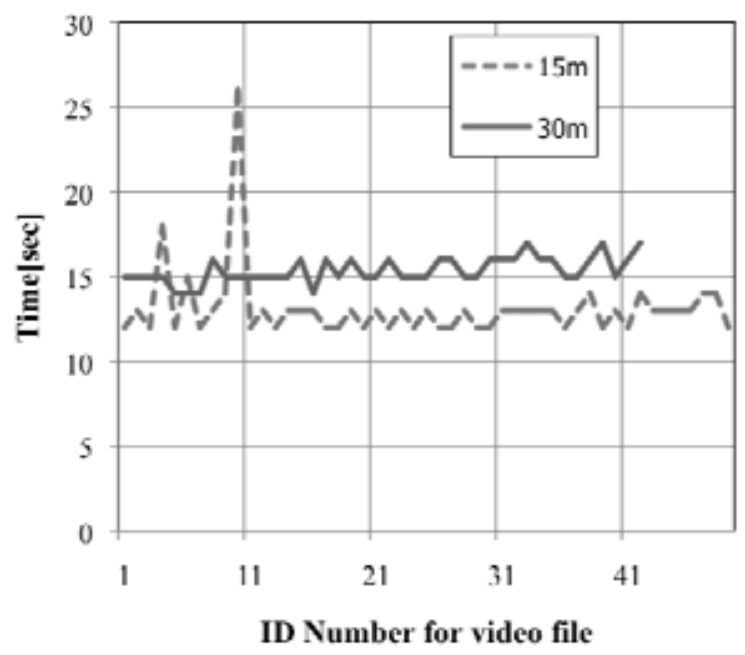

Fig. 10. Video File Transferring Performance

The experimental results thus verify the capability of the camera node for effective acquisition and transmission of information on the surroundings at the camera node site.

\subsection{Experiment on information gathering in ad hoc network}

The next experiment was performed to verify the basic capability for multihop transmission of site information (i.e., video images) acquired by individual camera nodes via the ad hoc wireless camera network constructed by two or more camera nodes. As shown in Fig. 11, the experiment was performed in the minimal two-hop configuration at outdoor environment, using a notebook PC with a wireless LAN adaptor and two camera nodes (Node 1 and Node 2; Fig. 12). Direct communication between the PC and Node 2 was blocked by the building, necessitating two-hop transmission. The PC served as the host for consolidation of the acquired image data, Node 1 as the relay station, and Node 2 as the information acquisition node and FTP uploader to the host PC via Node 1.

A file size of $360 \mathrm{kB}$ was used for the video data (ASF format, $352 \times 288$ resolution, video playback time $5 \mathrm{sec}$ ), uploaded in a hop configuration with data acquisition by Node 2, transmittted to Node 1 and then from Node 1 to the PC, followed by a 15-s interval and then initiation of the next transmission, in a repeating sequence over a 40-min time period.

Table 2 is a typical routing table for the output by Node 2 (IP address 192.168.1.249) using AODV-UU in the video transmission. As this table shows, the destination was 192.168.1.200, which is the $\mathrm{IP}$ address of the PC, and the next hop designation was 192.168 .1 .103 , the $\mathbb{P}$ address of Node 1, thus confirming that the data transmitted by Node 2 was routed to the $\mathrm{PC}$ via Node 1 . In the experiment, Node 2 transmitted captured videos, all of which were 
received by the PC. Thus, the remote site information was transmitted over two hops with no difference in file size, indicating that the information acquired on-site was transmitted effectively via the ad hoc wireless network constructed by the camera nodes. Fig. 14 shows network performance for transmitting the video files. Average time of transferring video files is 23.1[sec] and average throughput value is $16.2[\mathrm{KByte} / \mathrm{sec}]$.

Fig. 15 shows the behavior related to actual packet transmission. Retransmitting data and route error were happened frequently. Camera node retransferred the video data and deliver video data via wireless ad-hoc network.

Finally, Fig. 16 shows the examples for browsing collected video files that are registered to Geographic Information System (GIS), actually 'Google Earth', based on GPS information. As mentioned above, GPS information is included in each file name and it is utilized to register the data to GIS. When the operator click the thumbnail on the interface, it is to play specified video file.
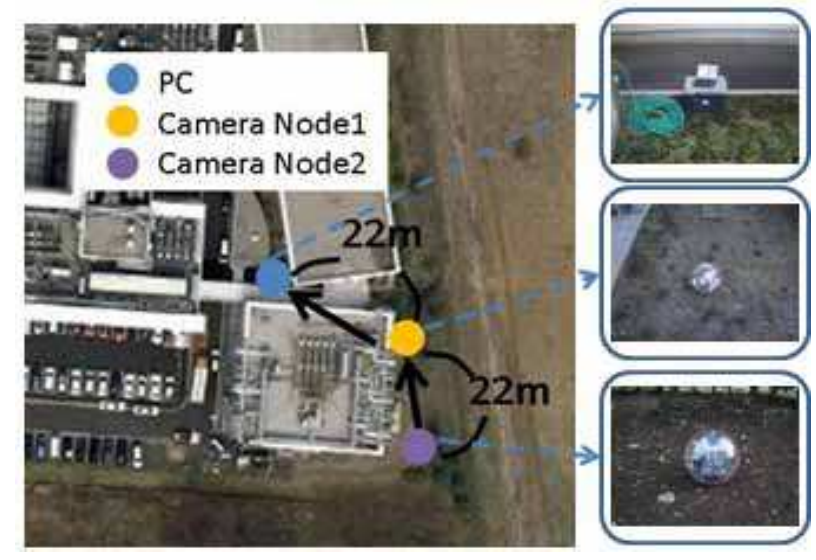

Fig. 11. Set up for Two-hop Communication Experiment
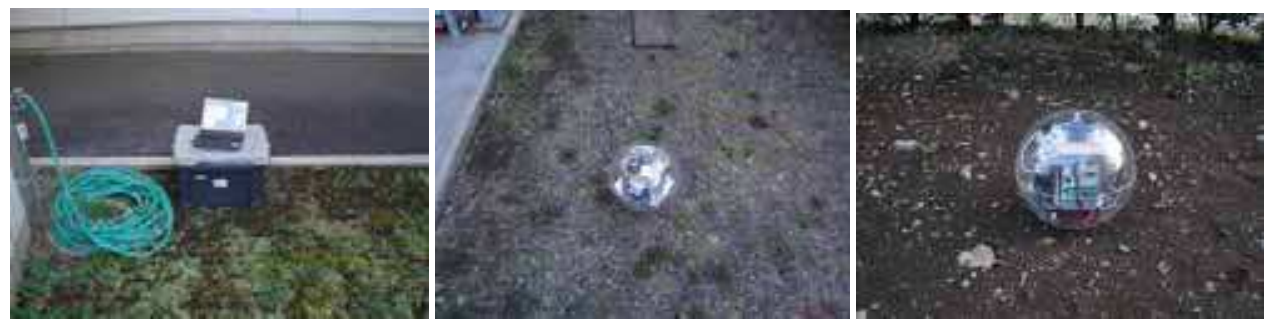

Fig. 12. Experimental Devices (Laptop PC, Camera Node1 and Camera Node2)

\begin{tabular}{|l|l|l|l|l|l|}
\hline \# Time: 17:41:42.244 IP: 192.168.1.105, sequence no: 136 entries/ active: 2/ 2 \\
\hline Destination & Next hop & HC & $\begin{array}{l}\text { St.Sequence } \\
\text { No. }\end{array}$ & Expire Flags & $\begin{array}{l}\text { Interface } \\
\text { Precursors }\end{array}$ \\
\hline 192.168.1.200 & 192.168 .1 .110 & 2 & VAL 183 & 2940 & Eth0 \\
\hline 192.168 .1 .110 & 192.168 .1 .110 & 1 & VAL 34 & 2934 & Eth0 \\
\hline
\end{tabular}

Table 2. Organized Routing Table 


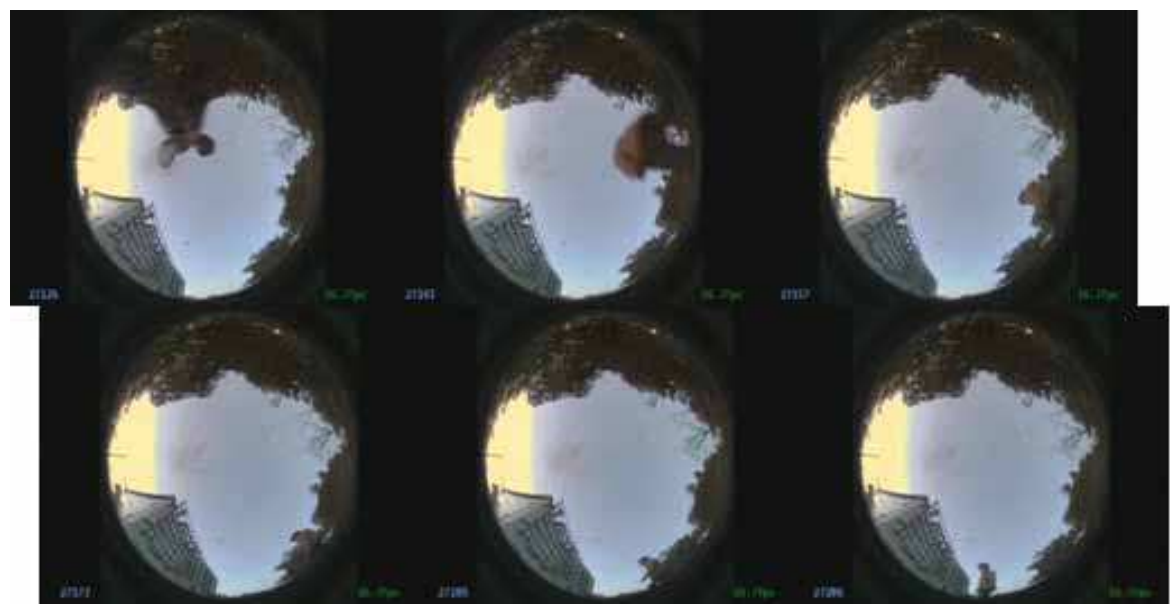

Captured video file name: 2008.02.28.17.12.22.3546.6918,N,13936.5564,E.5.rcomm1.ASF Fig. 13. Examples of Captured and Transferred View by Camera node 2

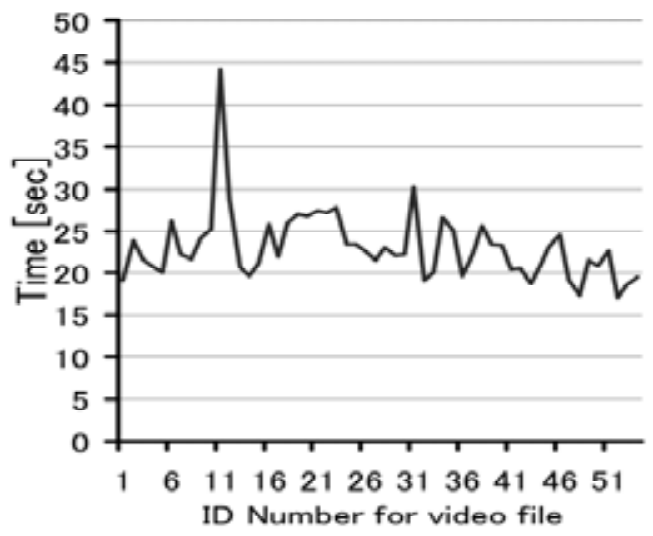

Fig. 14. Network performance

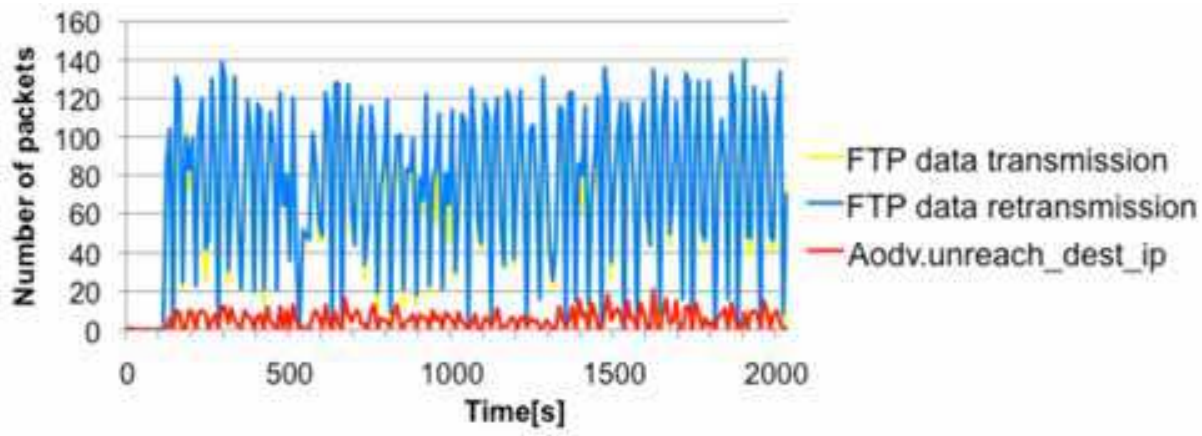

Fig. 15. Behavior of network packet 

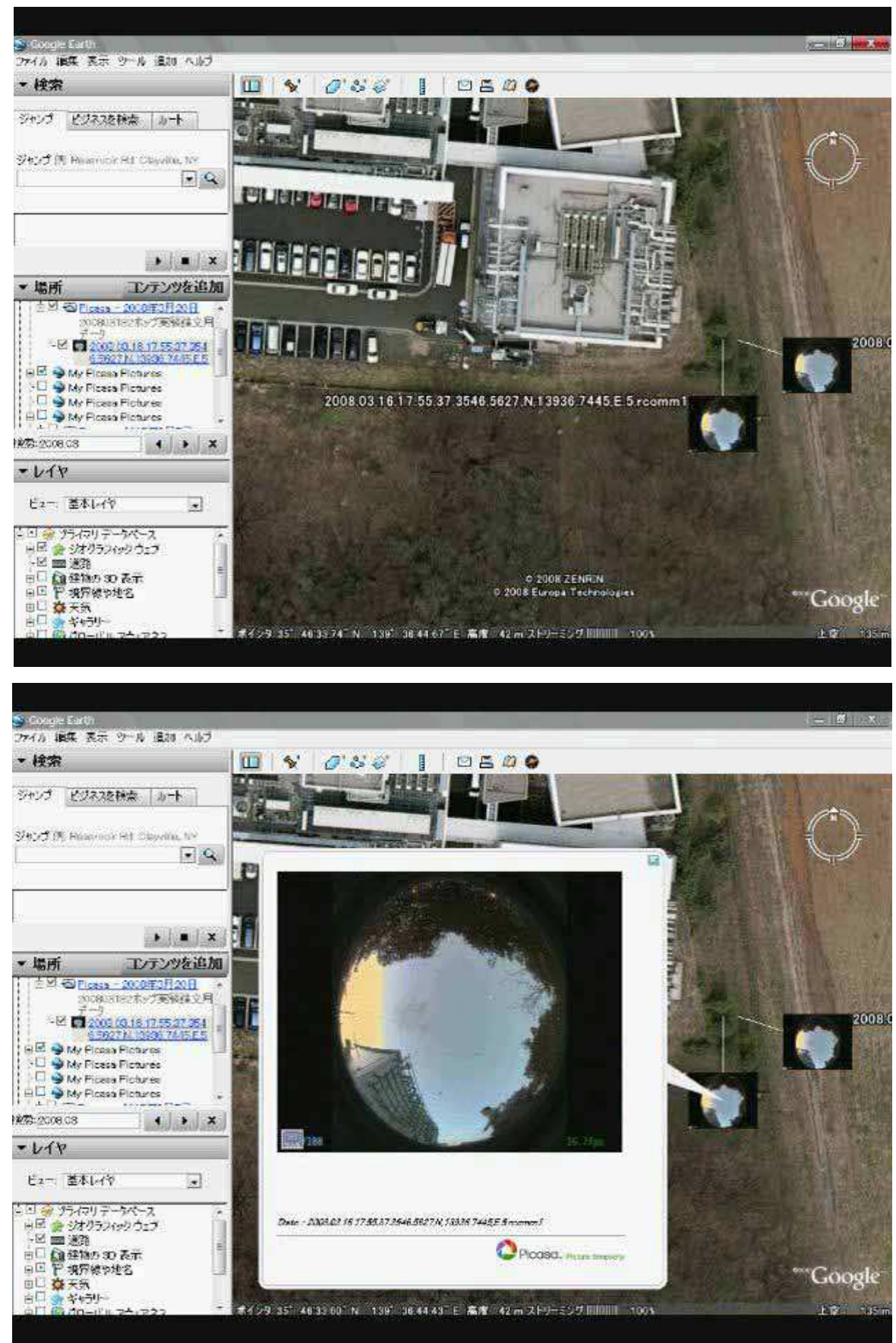


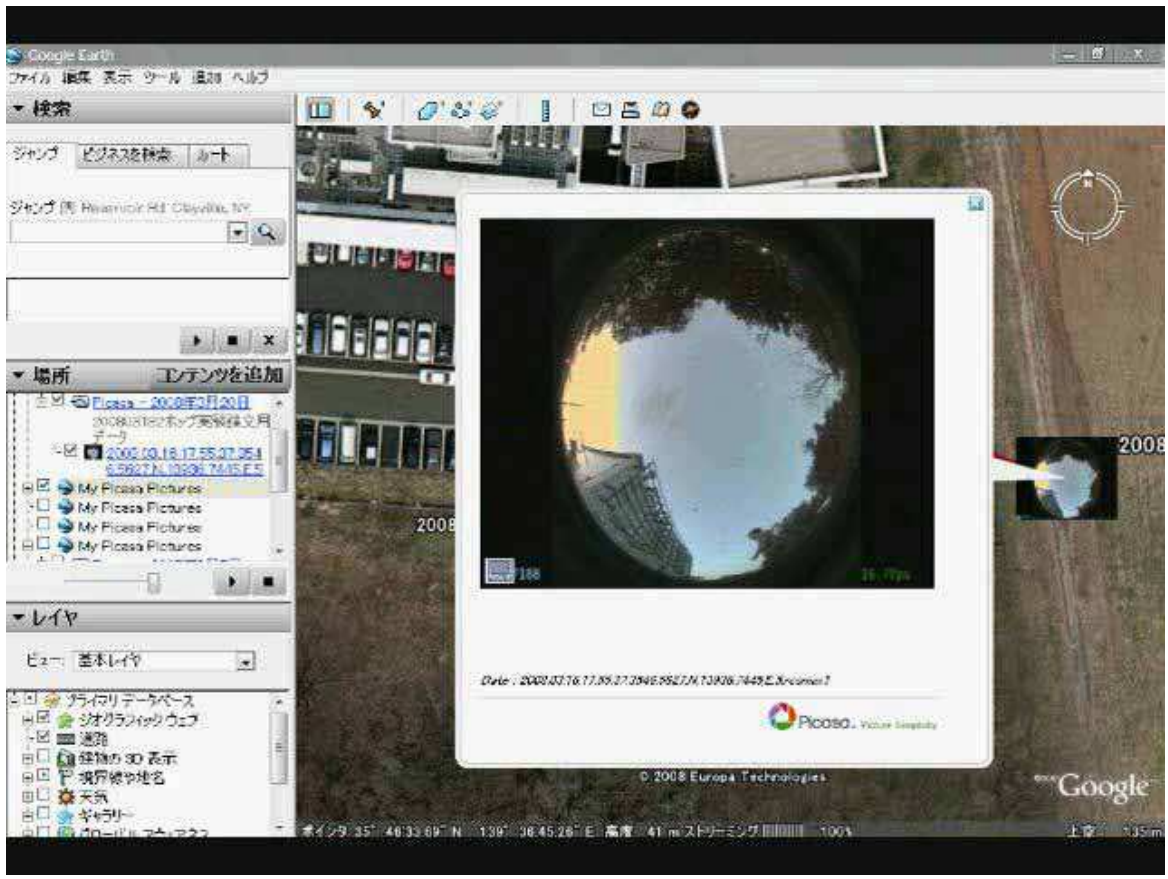

Fig. 16. Registered video files to GIS

\section{Conclusion}

In this report, we have proposed a sensor node and related wireless network for information gathering in disaster areas. We have described a "camera node" prototype developed on this basis, containing a camera with a fisheye lens, a passive self-righting mechanism to maintain the camera orientation, and the systems capability for construction of an ad hoc wireless network, together with a GPS adaptor and an embedded computer timer to identify its position and imaging time. The camera node is relatively easy to deploy and enables acquisition and consolidation of temporally and spatially coherent information on disaster areas. These functions were verified in experiments with this camera sensor prototype. Utilizing prototypes data transmission experiment was done and ad-hoc network construction and stable video data transmission were also verified.

We are planning to incorporate modifications to enable more accurate adjustment of the embedded camera attitude. In addition, although a transparent acrylic shell was used in the prototype for the experiments described in this report, we are considering the use of polycarbonate or other impact-resistant material for the shell to increase its durability under dropping or impact from falling debris and rubble. We intend to investigate the development of systems for deployment, retrieval, and redeployment of the camera-bearing nodes and networks by robots or other automated equipment, utilizing the relative ease and simplicity of deployment characteristic of these sensor nodes and the consequent freedom from a need for complex deployment control equipment or procedures. Investigation is also in progress for further reduction of their size and weight, and discussions will be necessary to determine their optimum size for use in disaster areas. 


\section{Reference}

Tadokoro, S. (2009). Rescue Robotics: DDT Project on Robots and Systems for Urban Search and Rescue, Springer, ISBN-10: 1848824734, London

Weiser, M., (1991). The Computer for the Twenty-First Century, Scientific American, 94-10

Takeda H. (1991).Data Carrier, Nihon kogyo shinbun sha, (in clopanese)

Kurabayashi, D., Noda, K., Asama, H., Kawabata, K., Kaetsu, H., and Hashimoto, H. (2003): Information Assistance for Search-and-Rescue by Intelligent Data Carriers and a Data Retrieval Blimp, eburnal of Robotics and Mechatronics, 15, 5 , 521-527

Asama, H., Hada, Y., Kawabata, K. (2005). "Overview of Information Infrastructure and Ubiquitous Devices for Victim Search" Proceedings of the 2nd International Conference on Ubiquitous Robots and Ambient Intelligence (URAmI'05), KRW056

Kaw abata, K., Hada, Y., Kaetsu, H., Asama, H. (2006).”Ubiquitous Victim Search Device : Intelligent Data Carrier for Rescue", Proceedings of IEEE Conference on Robotics and Automation, 4306-4308

Hada, Y., Kawabata, K., Kaetsu, H., Koguchi, H., Asama, H., (2006). "Rescue Communicators for Grobal Victim Search and Local Rescue Planning", Proceedings of IEEE/RSJ International Conference on Intelligent Robots and Systems, 3510-3513

Takizawa, O., Shibayama, A., Hosokawa, M., Takanashi, K., Murakami, M., Hisada, Y., Hada, Y., Kawabata, K., Noda, I., Asama, H., (2007). Hybrid Radio Frequency Identification System for Use in Disaster Relief as Positioning Source and Emergency Message Boards, Mobile Response, LNCS 4458, 85-94, ISNN: 0302-9743

Inoue, K., Yamamoto, M., Mae, Y., Takubo, T., Arai, T. (2005). Search Balls: Sensor Units for Searching Inside of Rubble, Advanced Robotics, 19, 8 , 861 - 878

Ando, S., Tamura, Y., Tobe, Y., Minami, M., (2005), Sensor Network Technology, Tokyo Denki Press (in clopanese)

Fukatsu, T. \& Hirafuji, M. (2005). Field Monitoring Using Sensor-Nodes with a Web Server, cburnal of Robotics and Mechatronics, 17, 2, 164-172

Nakata, M., \& Kushiro, N., (2007). Practical Solution for Constructing Sensor Network in Building and Home Control System, eburnal of the Robotics Society of Japan, 25, 4, 530533

Chemel, B., Mutshler, E., Schempf, H. (1991). Cyclops : Miniature Robotic Reconnaissance System, Proc. of the 1999 IEEE International Conference on Robotics and Automation, 2298-2302

Schempf, H., Mutshler, E., Chemel, B., Nayar, S., Piepgras, C., Crowley, W., Boehmke, S. (1999). Evolution of Urban Robotic System Development, Proceedings of the 1999 IEEE/ASME International Conference on Advanced Intelligent Mechatronics, 689-694

Hada, Y., Kawabata, K. Kaetsu, H., Koguchi, H., Asama, H. (2006). Rescue Communicators for Grobal Victim Search and Local Rescue Planning, Proceedings of IEEE/RSJ International Conference on Intelligent Robots and Systems, 3510-3513

Suzuki, T., Sugizaki, R., Kawabata, K., Hada, Y., Tobe, Y. (2008). Development and Management of Wireless Sensor Network using Mobile Robots for Gathering Environment Information”, Distributed Autonomous Robotic Systems 8, Asama, H.; Kurokawa, H.; Ota, J.; Sekiyama, K. (Eds.), 63-72, ISBN: 978-3-642-00643-2 


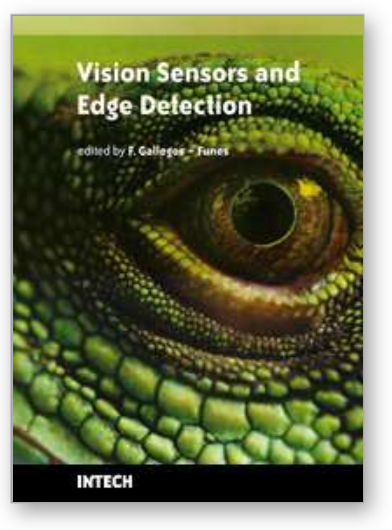

\author{
Vision Sensors and Edge Detection \\ Edited by Francisco Gallegos-Funes
}

ISBN 978-953-307-098-8

Hard cover, 196 pages

Publisher Sciyo

Published online 12, August, 2010

Published in print edition August, 2010

Vision Sensors and Edge Detection book reflects a selection of recent developments within the area of vision sensors and edge detection. There are two sections in this book. The first section presents vision sensors with applications to panoramic vision sensors, wireless vision sensors, and automated vision sensor inspection, and the second one shows image processing techniques, such as, image measurements, image transformations, filtering, and parallel computing.

\title{
How to reference
}

In order to correctly reference this scholarly work, feel free to copy and paste the following:

Kuniaki Kawabata, Hideo Sato, Tsuyoshi Suzuki and Yoshito Tobe (2010). A Wireless Camera Node with Passive Self-righting Mechanism for Capturing Surrounding View, Vision Sensors and Edge Detection, Francisco Gallegos-Funes (Ed.), ISBN: 978-953-307-098-8, InTech, Available from:

http://www.intechopen.com/books/vision-sensors-and-edge-detection/a-wireless-camera-node-with-passiveself-righting-mechanism-for-capturing-surrounding-view

\section{INTECH}

open science | open minds

\section{InTech Europe}

University Campus STeP Ri

Slavka Krautzeka 83/A

51000 Rijeka, Croatia

Phone: +385 (51) 770447

Fax: +385 (51) 686166

www.intechopen.com

\section{InTech China}

Unit 405, Office Block, Hotel Equatorial Shanghai

No.65, Yan An Road (West), Shanghai, 200040, China

中国上海市延安西路65号上海国际贵都大饭店办公楼 405 单元

Phone: +86-21-62489820

Fax: $+86-21-62489821$ 
(C) 2010 The Author(s). Licensee IntechOpen. This chapter is distributed under the terms of the Creative Commons Attribution-NonCommercialShareAlike-3.0 License, which permits use, distribution and reproduction for non-commercial purposes, provided the original is properly cited and derivative works building on this content are distributed under the same license. 